\title{
Media Exposure, Disaster Experience, and Risk Perception of Rural Households in Earthquake-Stricken Areas: Evidence from Rural China
}

\author{
Dingde $X u^{1, *,+} \oplus$, Linmei Zhuang ${ }^{2,+}$, Xin Deng ${ }^{3} \mathbb{C}$, Cheng Qing $^{2}$ and Zhuolin Yong ${ }^{2}$ \\ 1 Sichuan Center for Rural Development Research, College of Management of Sichuan Agricultural University, \\ Chengdu 611130, China \\ 2 College of Management of Sichuan Agricultural University, Chengdu 611130, China; \\ zhuanglinmei@stu.sicau.edu.cn (L.Z.); qingchen@stu.sicau.edu.cn (C.Q.); \\ zhuolinyong@stu.sicau.edu.cn (Z.Y.) \\ 3 College of Economics of Sichuan Agricultural University, Chengdu 611130, China; dengxin@sicau.edu.cn \\ * Correspondence: dingdexu@sicau.edu.cn; Tel.: +86-13408598819 \\ + These authors contributed equally to this work and should be considered co-first authors.
}

Received: 6 April 2020; Accepted: 29 April 2020; Published: 6 May 2020

\begin{abstract}
For effective communication and management of disaster risks, it is important to explore how media exposure and disaster experience related to earthquake events affect residents' prospect ranks of disaster risk perceptions. Using survey data from 327 households located in the Wenchuan and Lushan earthquake regions in China, the ordinary least square method was used to explore the associations among media exposure, severity of disaster experience, and residents' perception of prospect ranks of the possibility and severity of disasters. The results showed the following. (1) Rural households relied predominately on television broadcasts from traditional media, and on mobile phones and internet content from new media to obtain disaster information. From the residents surveyed, $90 \%$ believed that a disaster experience was serious, $82 \%$ considered that another major earthquake would seriously affect their lives and property, while approximately $40 \%$ of the residents did not believe there would be another major earthquake in the next 10 years. (2) Media exposure was negatively correlated with the perceived prospect ranks of the probability and severity of disasters, with traditional media exposure significantly negatively correlated with the perceived prospect ranks of the severity of disasters and new media exposure significantly negatively correlated with the perceived prospect ranks of the probability of disasters. Severity experience was significantly and positively correlated with the perceived prospect ranks of the probability and severity of disasters. (3) New media exposure moderated the relationship between residents' disaster experience and their perception of prospect ranks of the severity of disasters. This study can help deepen our understanding of disaster risk communication and better guide the practice of disaster risk management.
\end{abstract}

Keywords: media exposure; disaster experience; risk perception; earthquake; Sichuan province; rural China

\section{Introduction}

Faced with the threat of natural disasters, many empirical studies have shown that effective and adequate disaster preparedness plays an important role in preventing the loss of life and damage to property [1-5]. For example, Godschalk et al. [6] found that a $\$ 1$ investment in disaster relief can yield a $\$ 4$ gain. However, studies have found that residents in vulnerable communities (communities with limited resources and which are often threatened and impacted by earthquakes and their secondary 
disasters) are not adequately prepared for external disasters (e.g., [7-9]). One important reason for this is the lack of effective communication of information to people who perceive the disaster risk to be of a low level. Media exposure is one of the most essential methods for residents to obtain disaster information $[7,10]$. With an increasing occurrence of global disasters, it is important to understand the types of media platforms that residents generally use to obtain disaster information and how frequently these platforms are accessed [11,12], especially for vulnerable rural households in developing countries.

The perception of disaster risk is an important driving factor to consider for understanding the behavioral decisions that residents make in disaster-prone areas. Therefore, research on the factors influencing disaster risk perception has become an essential topic in the disaster risk management field [13-15]. Many studies have focused on the impact of individual (e.g., [16-18]), family socio-economic (e.g., [19,20]) and village characteristics (e.g., [21,22]) on residents' disaster risk perceptions. Because it is an important factor that affects residents' risk perceptions, disaster information is often incorporated into models as a control variable (e.g., [23,24]). However, few empirical studies have specifically focused on the impact that media exposure has on residents' risk perceptions of disasters [10,12] and few studies have explored the associations among traditional and new media exposure and residents' disaster risk perceptions [10]. Current studies take media exposure and residents' disaster experience as indicators that directly affect residents' disaster risk perceptions. However, few empirical studies have confirmed that there is a moderating effect between media exposure and disaster experience that indirectly affects residents' disaster risk perception [10]. In China's vast earthquake disaster threat areas, further research is required to understand the moderating effect between media exposure and disaster experience, and how these affect residents' disaster risk perception.

China is a large country with mountainous areas, where a large number of people live [25-27]. Affected by geological movement, China has suffered frequent earthquake disasters in recent years, causing a large number of deaths, serious damage to property, and far-reaching impacts on social and economic development. In the past 10 years, the country has experienced 159 earthquakes of at least magnitude 5 on the Richter scale. Among these, there have been seven major earthquakes with magnitudes above 7, 26 strong earthquakes with magnitudes between 6 and 6.9, and 83 moderate earthquakes with magnitudes between 5 and 5.9 (Figure 1). These earthquake disasters resulted in more than 48,000 casualties and 1.13 trillion Yuan in economic losses. The Wenchuan and Lushan earthquakes were the deadliest among the seven major earthquakes. For instance, the Wenchuan earthquake in 2008 caused about 450,000 casualties and direct economic losses as high as 845.2 billion Yuan [28]. The disaster risk management of China's Sichuan earthquake disaster area was relatively small; therefore, relevant research is urgently required [24,29].

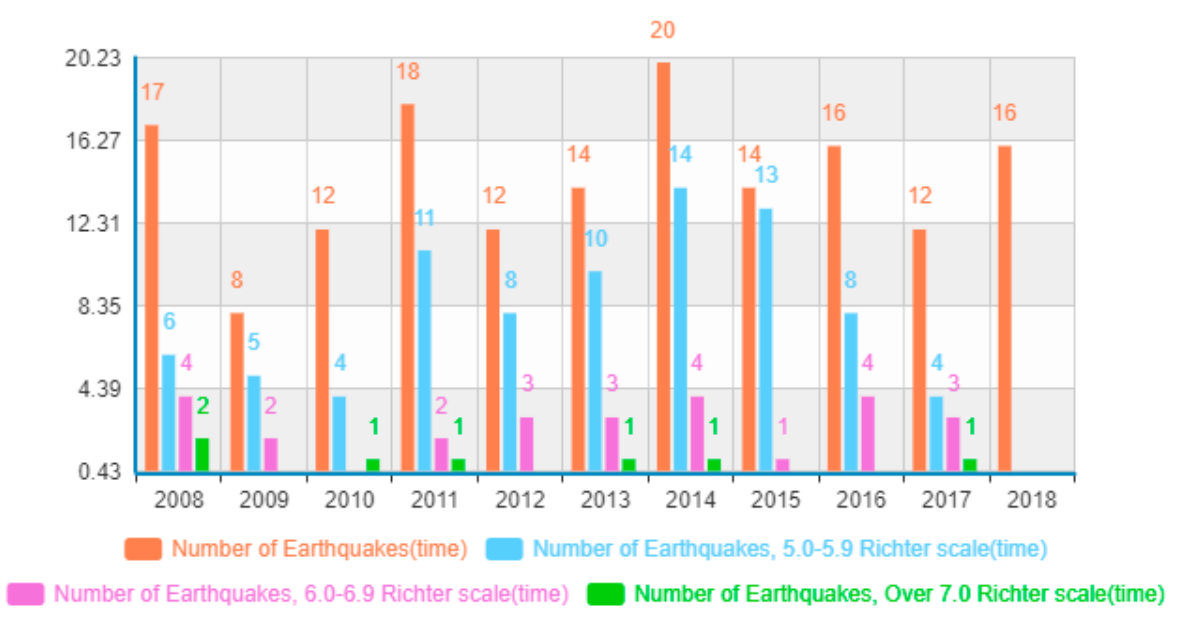

Figure 1. Statistics on the number of earthquakes in China from 2008 to 2018. 
The present study focused on the areas most damaged by the Wenchuan and Lushan earthquakes in Sichuan province, China. The first main objective was to analyze the media exposure, disaster experience and disaster risk perception characteristics of residents in the worst-hit earthquake areas. The second objective was to build an econometric model to explore the correlation among media exposure, disaster experience, and prospect ranks of disaster risk perception, and to further subdivide the types of media exposure (traditional and new media).

\section{Theoretical Development}

The purpose of this study is to explore the correlation between media exposure, residents' disaster experience and residents' prospect ranks of disaster risk perception in the earthquake disaster threat area. In this study, media exposure refers to the channels through which the residents of the earthquake disaster threat area obtain disaster information at different stages of the disaster, which can be specifically divided into new media exposure and old media exposure [10]. Among them, new media exposure refers to the disaster information obtained by residents mainly through new media channels (mobile phones and the Internet), while old media exposure refers to the disaster information obtained by residents mainly through traditional channels (TV, magazines, newspapers, radio). Residents' disaster experience refers to the severity of the impact of the most severe earthquake disaster on their family in their memory $[24,29]$. Residents' perception of disaster risk refers to their attitude towards disaster risk and their intuitive judgment of disaster risk [24,29]. In the follow-up part of this part, the study will systematically sort out the existing studies on the correlation between media exposure, residents' disaster experience and residents' prospect ranks of disaster risk perception, and put forward the research hypothesis of this study on this basis.

\subsection{Media Exposure and Perceived Prospect Ranks of Disaster Risk Perception}

In the face of disaster threats, media exposure is one of the most important ways for residents to judge and understand disaster information [10,12,30,31]. Media exposure has multiple functions in the formation of disaster risk perception, such as communicating information before, during, and after the disaster; encouraging residents to learn disaster knowledge and skills; and establishing public responsibility and safety culture [10,32-34]. The speed of accurately reporting and disseminating information by the media will affect residents' perception of disaster risk, and thus affect their behavioral decisions $[35,36]$. Meanwhile, the rapid spread of disasters in a certain area will further convey social norms [10,32]; through communication among the public, a culture of responsibility and safety can be established to improve public awareness of disaster prevention and risk reduction $[10,32,37,38]$. In addition, people in disaster-prone regions will learn about disaster prevention and risk reduction knowledge, and how to prepare for disasters in advance [39-41].

From the analysis of information channels (such as Internet, TV, newspapers, radio, etc.,) to the formation process of residents' disaster risk perception, it can be seen that residents' disaster risk perception is closely related to the frequency of information received (including the speed of transmission) and the quality of information (information credibility and usefulness) [31,42]. Modern society is an information age society, where traditional media and new media coexist $[36,43]$. Due to the characteristics of fast transmission speed and low cost, new media has become increasingly important in the field of disaster risk communication [31,44], and, especially when residents think that the mainstream media cannot provide enough information, the use of new media plays a crucial role in the effective transmission and communication of disaster information [31,42,45]. In essence, channel residents choose to obtain information from or rely more on certain channels in order to accurately grasp the actual situation of disasters and reduce the uncertainty in the process of disaster information transmission $[7,10]$. From the existing studies, it is generally believed that media exposure can significantly improve the disaster risk perception of residents $[10,34,46,47]$; media exposure here includes both traditional media exposure and new media exposure. For example, Fleming et al. [46], Morton and Duck [47] found that traditional media exposure, such as to newspapers, has a positive 
significant effect on residents' disaster risk perception; Zhu and Yao [34] found that new media exposure has a positive influence on residents' disaster risk perception; Hong et al. [10] also found that the media exposure (including traditional and new media exposure) has a positive significant effect on the perceived severity of disasters. As such, this research proposes hypothesis 1 (H1, H1a, H1b) (Figure 2).

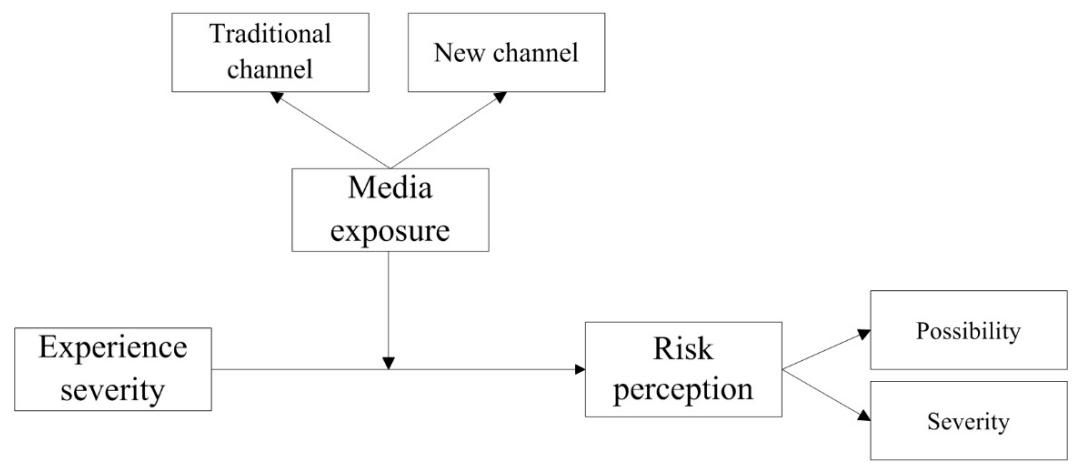

Figure 2. Theoretical framework of media exposure, disaster experience severity and risk perception.

H1: Media exposure is significantly and positively correlated with the perceived prospect ranks of probability and severity of disasters.

H1a: Traditional media exposure is significantly and positively correlated with the perceived prospect ranks of probability and severity of disasters.

H1b: New media exposure is significantly and positively correlated with the perceived prospect ranks of probability and severity of disasters.

\subsection{Disaster Experience and Perceived Prospect Ranks of Disaster Risk Perception}

Many empirical studies show that residents' disaster risk perception will be affected by their direct or indirect disaster experience $[10,22,48]$. For people with rich disaster experience, when the disaster occurs again, theoretically, they can quickly judge the disaster situation based on their previous experience, that is, people with rich disaster experience generally have more rational disaster risk perception $[10,22]$. They will obtain disaster information through media and other channels and make reasonable decisions on disaster prevention and mitigation [10]. Therefore, in existing studies, most scholars believe that disaster experience is significantly and positively correlated with disaster risk perception (e.g., [12,48,49]). For example, Xu et al. [22] found that there was a positive correlation between residents' landslide disaster experience and the perceived probability of disasters. Botzen et al. [50] found that there was a positive correlation between residents' flood disaster experience and their risk perception and insurance needs. However, for people without disaster experience, they usually construct their disaster risk perception through disaster information obtained from the outside world, and then make decisions on disaster prevention and reduction. At this point, the external information may completely magnify their perception of disaster risk. Therefore, some studies have found that media information has an impact on residents' disaster risk perception, but such impact is only significant in the group with low disaster experience [51]. Additionally, a few studies have found that the correlation between residents' disaster experience and disaster risk perception is not significant (e.g., $\mathrm{Xu}$ et al. [22]). However, most studies believe that there is a significant positive correlation between the two. Based on this, this research proposes hypothesis 2 (H2) (Figure 2).

H2: Residents' disaster experience is positively correlated with the perceived prospect ranks of probability and severity of disasters. 
2.3. Media Exposure Moderates the Relationship between Residents' Disaster Experience and Perceived Prospect Ranks of Disaster Risk Perception

Most studies suggest a significant positive correlation between residents' disaster experience and perceived prospect ranks of disaster risk perception. However, some studies suggest that this correlation is indirect. For example, faced with the threat of disasters, Hong et al. [10] believed that individuals with adequate disaster experience could identify disaster information more calmly and effectively, and respond with quicker behavioral decisions. The more pronounced the residents' disaster experience was, the weaker the correlation between media exposure and perceived prospect ranks of disaster risk perception. Kasperson et al. [52] argued that individuals lacking disaster experience would rely more on the content of external information to magnify their perception of disaster risk (for example, they may think that disasters are more likely to occur and be more serious). Based on this, this research proposes hypothesis 3 (H3, H3a, H3b) (Figure 2).

H3: Media exposure moderates the relationship between residents' disaster experience and their perceived prospect ranks of possibility and severity of disasters. When disaster experience is high, the positive relationship between media exposure and the perceived prospect ranks of possibility and severity of disasters are strong.

H3a: Traditional media exposure moderates the relationship between residents' disaster experience and their perceived prospect ranks of possibility and severity of disasters. When disaster experience is high, the positive relationship between traditional media exposure and the perceived prospect ranks of possibility and severity of disasters are strong.

H3b: New media exposure moderates the relationship between residents' disaster experience and their perceived prospect ranks of possibility and severity of disasters. When disaster experience is high, the positive relationship between new media exposure and the perceived prospect ranks of possibility and severity of disasters are strong.

\section{Material and Methods}

\subsection{Data Sources}

The data used in this research were mainly acquired from a questionnaire survey conducted by the research group in areas affected by the Lushan and Wenchuan earthquakes in July 2019. The study used one-on-one interviews to evaluate behavioral responses to disaster risk perception and disaster preparedness. To ensure that representative and non-biased samples were tested, stratified random sampling was performed. A total of 327 households were investigated from 16 villages of eight townships in four counties. For a detailed introduction, please refer to $\mathrm{Xu}$ et al. [24]. See Figure 3 for the location of the sample counties and towns.

\subsection{Measures}

\subsubsection{Media Exposure}

Media exposure mainly reflects public access to media information in the worst-hit earthquake areas. Referring to the studies by Fleming et al. [46], Hong et al. [10] and Lee [32], this research divided rural household media exposure into traditional and new media forms. Traditional media includes newspapers, magazines, radio, and television, while new media includes mobile phones and the internet. These variables were measured by asking residents how often they used these media platforms (Table 1). After obtaining this information, the indicators of traditional and new media exposure were summed and averaged, and the mean value was substituted for the scores of the two groups, as performed by Hong et al. [10]. At the same time, all indicators representing media exposure were summed and averaged, and their mean value was substituted for media exposure. 


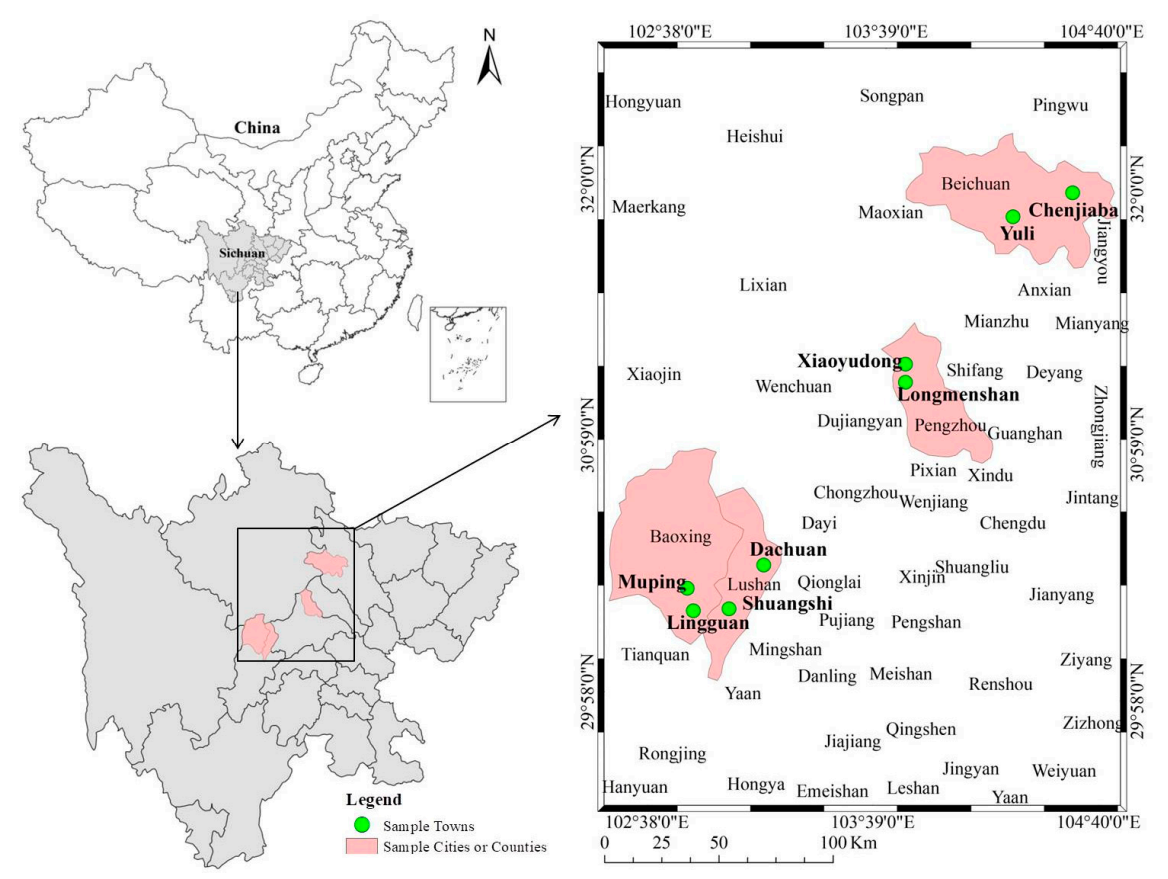

Figure 3. Location map of sample counties and towns (Figure source please see [53]).

Table 1. Definition and descriptive statistics of the variables in the model.

\begin{tabular}{|c|c|c|c|c|c|}
\hline Category & Variable & Definition and Measure & Mean & Median & $\mathrm{SD}^{\mathrm{e}}$ \\
\hline \multirow[t]{2}{*}{ Risk perception } & Possibility & $\begin{array}{l}\text { There may be a big earthquake near your home in the next } \\
\qquad 10 \text { years }{ }^{\text {a }}\end{array}$ & 2.83 & 3.00 & 1.12 \\
\hline & Severity & $\begin{array}{c}\text { An earthquake in the future will have a serious impact on } \\
\text { villages and rural households }{ }^{b}\end{array}$ & 4.19 & 3.00 & 1.12 \\
\hline \multirow{6}{*}{$\begin{array}{l}\text { Media } \\
\text { exposure }\end{array}$} & $\begin{array}{l}\text { Traditional } \\
\text { channel }\end{array}$ & How often do you read newspapers? ${ }^{c}$ & 1.07 & 3.00 & 0.40 \\
\hline & $\begin{array}{c}\text { Traditional } \\
\text { channel }\end{array}$ & How often do you read a magazine? ${ }^{c}$ & 1.06 & 3.00 & 0.44 \\
\hline & $\begin{array}{l}\text { Traditional } \\
\text { channel }\end{array}$ & How often do you listen to the radio? ${ }^{c}$ & 1.09 & 3.00 & 0.51 \\
\hline & $\begin{array}{l}\text { Traditional } \\
\text { channel }\end{array}$ & How often do you watch TV? ${ }^{c}$ & 3.67 & 3.00 & 1.24 \\
\hline & New channel & How often do you use your mobile phone? ${ }^{c}$ & 2.12 & 3.00 & 1.58 \\
\hline & New channel & How often do you use the Internet? ${ }^{c}$ & 2.90 & 3.00 & 1.66 \\
\hline $\begin{array}{l}\text { Disaster } \\
\text { Experience }\end{array}$ & $\begin{array}{l}\text { Experience } \\
\text { severity }\end{array}$ & The severity of residents' disaster experience ${ }^{b}$ & 4.56 & 3.00 & 0.76 \\
\hline \multirow{6}{*}{$\begin{array}{l}\text { Individual } \\
\text { characteristics }\end{array}$} & Gender & Responder gender $(0=$ male, $1=$ female $)$ & 0.46 & 0.00 & 0.50 \\
\hline & Age & Responder age (year) & 53.44 & 5.300 & 13.40 \\
\hline & Education & Years of education (year) & 6.29 & 6.00 & 3.70 \\
\hline & Residence & Length of residence of responder (year) & 41.71 & 45.00 & 19.78 \\
\hline & Nationality & Responder nationality $(0=$ other, $1=$ Han $)$ & 0.82 & 0.00 & 0.39 \\
\hline & Occupation & Responder occupation ( $0=$ other, $1=$ Farmer $)$ & 0.57 & 1.00 & 0.50 \\
\hline \multirow{4}{*}{$\begin{array}{l}\text { Household } \\
\text { characteristics }\end{array}$} & Income & Total annual cash income of rural households (Yuan ${ }^{\mathrm{d}}$ ) & $66,238.94$ & $46,200.00$ & $72,237.87$ \\
\hline & Old & $\begin{array}{l}\text { Whether the resident family comprises individuals over } \\
\qquad 64 \text { years of age }(0=\text { no, } 1=\text { yes })\end{array}$ & 0.48 & 0.00 & 0.50 \\
\hline & Child & $\begin{array}{l}\text { Whether the resident family has a child below } 6 \text { years of } \\
\text { age }(0=\text { no, } 1=\text { yes })\end{array}$ & 0.24 & 0.00 & 0.43 \\
\hline & House & Whether the house is a concrete structure $(0=$ no, $1=$ yes $)$ & 0.48 & 0.00 & 0.50 \\
\hline
\end{tabular}

Note: ${ }^{\mathrm{a}} 1$ = strongly disagree, $2=$ disagree, $3=$ average, $4=$ agree, $5=$ strongly agree; ${ }^{\mathrm{b}} 1=$ not very serious, $2=$ not serious, $3=$ general, $4=$ serious, $5=$ very serious; $^{\mathrm{c}} 1=$ never, $2=$ rarely, $3=$ average, $4=$ often, $5=$ very often; ${ }^{\mathrm{d}} 1 \mathrm{USD}=6.88$ Yuan (at the time of the study); ${ }^{\mathrm{e}} \mathrm{SD}=$ standard deviation. 


\subsubsection{Disaster Experiences}

On the measurement of disaster experience, academic standards are not uniform [24]. Referring to the studies of Lo and Cheung [54] and $\mathrm{Xu}$ et al. [24], this study measures the disaster experience of residents by the following questions: the severity of the impact of the most severe earthquake disaster on the family in your memory $(1=$ very not serious, $2=$ not serious, $3=$ average, $4=$ serious, $5=$ very serious).

\subsubsection{Risk Perception}

Disaster risk perception is a concept that describes people's attitude and intuitive judgment toward disaster risk [22,55]. There are two methods to measure disaster risk perception. The present study mainly followed the psychological measurement method, which presumes that residents' disaster risk perception is measurable and multi-dimensional. Following the outline by Lennart [56], Slovic [57], Thompson et al. [58], Peng et al. [23,59] and Xu et al. [29,48], this study measured disaster risk perception in two aspects: perceived probability of disaster and perceived severity of disaster. For each dimension, we chose one index to measure it. For example, regarding the measure of residents' perception of the possibility of disaster, we asked residents how much they agreed with the following statement: there may be a big earthquake near your home in the next 10 years $(1=$ strongly disagree, $2=$ disagree, $3=$ average, $4=$ agree, $5=$ strongly agree).

\subsubsection{Control Variables}

To improve the power of the model, some factors affecting residents' disaster risk perception were added as control variables, as performed by Armaş [16], Ho et al. [60], Huang et al. [61], Lazo et al. [62] and Lindell and Perry [20]. These included personal characteristics of study participants (e.g., gender, age, education, etc.), and social and economic characteristics of families (e.g., income, age, children, etc.).

\subsubsection{Analytic Strategy}

The dependent variable of the present study was residents' disaster risk perception, which included two indicators: probability and severity of disaster occurrence. Because these two variables are measured by 1-5-point Likert scales, which are regarded as interval variables, the ordinary least square method was used to make estimations of the model. The estimation formula is as follows:

$$
\mathrm{Y}_{i}=\alpha_{0}+\rho_{1 i} \times M E_{i}+\rho_{2 i} \times E S_{i}+\rho_{3 i} \times \text { Control }_{i}+\epsilon_{i}
$$

where $Y_{i}$ refers to the probability and severity of disasters respectively; $M E_{i}$ and $E S_{i}$ are core independent variables, which refer to media exposure and the severity of disaster experience; Control $_{i}$ represents the socio-economic characteristics of residents' individuals and families; $\alpha_{0}, \rho_{1 i}, \rho_{2 i}$ and $\rho_{3 i}$ represent model parameters to be estimated, respectively; $\epsilon_{i}$ refers to residual items.

\section{Results}

\subsection{Descriptive Statistical Analysis}

\subsubsection{Media Exposure}

Table 2 shows the distribution and frequency of media exposure. Television was the main traditional media source of disaster information for rural households (188 households; $57.49 \%$ ), with significantly less information coming from newspapers, magazines, and radio (less than $5 \%$ ). For new media forms, the internet and mobile devices were two important ways for rural households to obtain disaster information. In the research area, all mobile phones can surf the Internet. A total of 137 rural households (41.90\%) often obtain disaster information through mobile phones, while 81 households 
( $24.77 \%$ ) often obtain disaster information through the internet. In contrast, $42.82 \%$ and $66.97 \%$ of rural households rarely used mobile phones and the internet, respectively, to obtain disaster information.

Table 2. Distribution of media exposure frequency.

\begin{tabular}{|c|c|c|c|c|c|c|}
\hline \multicolumn{2}{|c|}{ Media Exposure } & Never & Rarely & Average & Often & Very Often \\
\hline \multirow{4}{*}{$\begin{array}{c}\text { Traditional } \\
\text { Channel }\end{array}$} & Newspapers & $314(96.02 \%)$ & $7(2.14 \%)$ & $3(0.92 \%)$ & $2(0.61 \%)$ & $1(0.31 \%)$ \\
\hline & Magazine & $319(97.55 \%)$ & $1(0.31 \%)$ & $4(1.22 \%)$ & $0(0.00 \%)$ & $3(0.92 \%)$ \\
\hline & Radio & $316(96.64 \%)$ & $3(0.92 \%)$ & $2(0.61 \%)$ & $3(0.92 \%)$ & $3(0.92 \%)$ \\
\hline & TV & $25(7.65 \%)$ & $29(8.87 \%)$ & $85(25.99 \%)$ & $77(23.55 \%)$ & $111(33.94 \%)$ \\
\hline \multirow{2}{*}{$\begin{array}{c}\text { New } \\
\text { Channel }\end{array}$} & $\begin{array}{l}\text { Mobile } \\
\text { phone }\end{array}$ & $118(36.09 \%)$ & $22(6.73 \%)$ & $50(15.29 \%)$ & $48(14.68 \%)$ & $89(27.22 \%)$ \\
\hline & Internet & $203(62.08 \%)$ & $16(4.89 \%)$ & $27(8.26 \%)$ & $29(8.87 \%)$ & $52(15.90 \%)$ \\
\hline
\end{tabular}

\subsubsection{Disaster Experiences}

Figure 4 shows the distribution and frequency of disaster experiences. For the Wenchuan or Lushan earthquakes, $90 \%$ of residents thought the disaster experience was serious, while only $2 \%$ of residents considered the disaster experience as not serious.

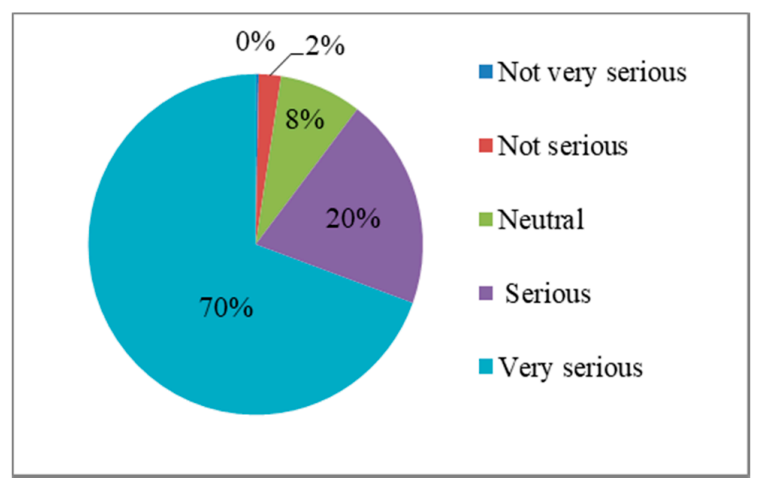

Figure 4. Distribution of disaster experiences frequency.

\subsubsection{Disaster Risk Perception}

Figure 5 shows the distribution of the perceived probability of events. Approximately $27 \%$ of residents thought that another major earthquake may occur in the next 10 years, while $40 \%$ of residents did not believe this. The remaining 33\% of residents were neutral. Figure 6 shows the distribution of perceived severity of events. Approximately $82 \%$ of the residents believed that another major earthquake will seriously affect their lives and safety of property, while $12 \%$ of the residents did not have these concerns. The remaining $6 \%$ of residents held a neutral attitude to this question.

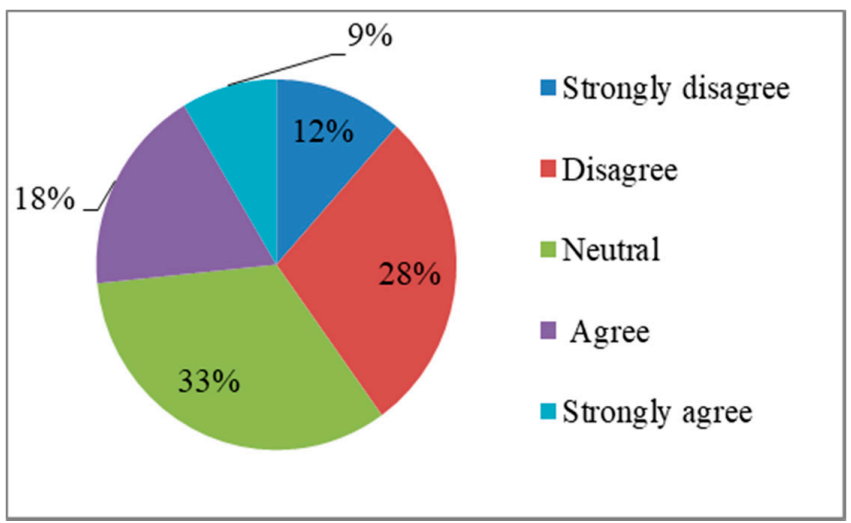

Figure 5. Another major earthquake may occur in the next 10 years. 


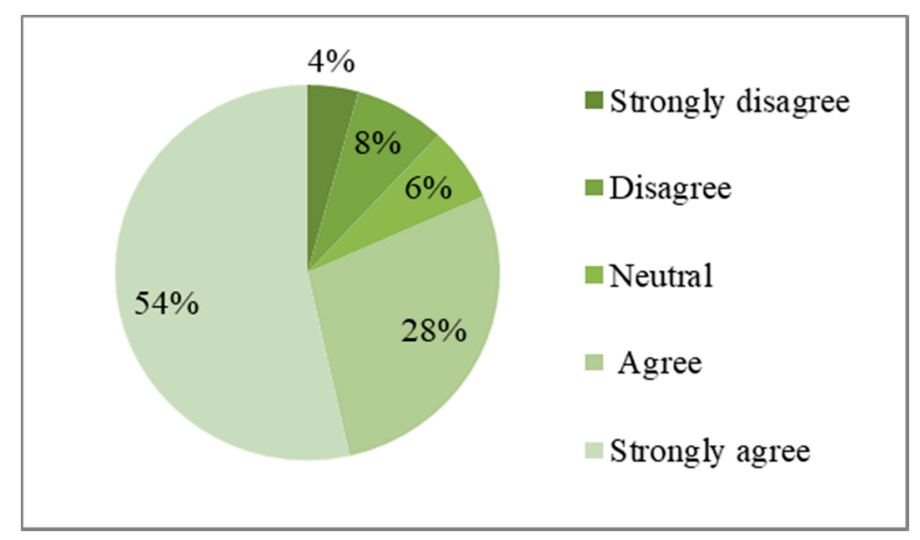

Figure 6. Another major earthquake will seriously affect residents' lives and safety of property.

\subsubsection{Control Variables}

As shown in Table 1, 54\% of the respondents were men, the average age was 53.4 years, the average length of education was 6.29 years, and the most common occupation was farming (57\%). The average cash income of the respondents' families was 66,239 Yuan. Almost half of households (48\%) included people over 64 years old, while nearly a quarter $(24 \%)$ included children under 6 years old. Almost half of the households surveyed lived in houses that were constructed of concrete (48\%).

\subsection{Correlation Analysis Among Independent Variables}

Table 3 shows the correlation coefficient matrix of the model variables. The correlation coefficient of each independent variable in the model was essentially below 0.5 ; therefore, there was no significant multicollinearity between the independent variables of the model. With regards to the correlation among media exposure, disaster experience and the perceived prospect ranks of the probability and severity of disasters, the perceived prospect rank of the probability of disasters was significantly negatively correlated with new media exposure and disaster experience, but not with traditional media exposure. The perceived prospect rank of the severity of disasters was significantly and positively correlated with traditional media exposure, while it was not significantly correlated with new media exposure.

Previous studies primarily focused on the correlation between core independent variables and dependent variables and did not control for other variables. The control of other variables, and making correlations between core independent variables and dependent variables, requires further analysis.

Previous studies primarily focused on the correlation between core independent variables and dependent variables and did not control for other variables. The control of other variables, and making correlations between core independent variables and dependent variables, requires further analysis.

\subsection{Regression Results}

Table 4 shows regression analysis results of media exposure, disaster experience and disaster risk perception. Models 1-3 show the regression results of independent variables and the perceived prospect ranks of the probability of disasters. Model 1 is the result when only independent variables concerned were included; Model 2 is the result when the moderating effect of media exposure and experience severity were included, based on Model 1; and Model 3 is the result when the control variables, such as individual and family socio-economic characteristics of respondents, were included, based on Model 2. Models 4-6 display the regression results of independent variables and the perceived severity of disaster, and the settings of each model are essentially the same as those of Models 1-3. 
Table 3. Correlation coefficient matrix of model variables.

\begin{tabular}{|c|c|c|c|c|c|c|c|c|c|c|c|c|c|c|c|}
\hline Variable & 1 & 2 & 3 & 4 & 5 & 6 & 7 & 8 & 9 & 10 & 11 & 12 & 13 & 14 & 15 \\
\hline 1 & 1 & & & & & & & & & & & & & & \\
\hline 2 & $0.199^{* * *}$ & 1 & & & & & & & & & & & & & \\
\hline 3 & -0.085 & $-0.158 * * *$ & 1 & & & & & & & & & & & & \\
\hline 4 & -0.203 **** & -0.068 & $0.119 * *$ & 1 & & & & & & & & & & & \\
\hline 5 & $0.154 * * *$ & $0.188^{* * *}$ & -0.068 & -0.007 & 1 & & & & & & & & & & \\
\hline 6 & -0.077 & 0.062 & -0.084 & 0.017 & 0 & 1 & & & & & & & & & \\
\hline 7 & $0.104 *$ & -0.047 & -0.058 & $-0.484^{* * *}$ & -0.017 & $-0.212 * * *$ & 1 & & & & & & & & \\
\hline 8 & -0.140 ** & -0.109 ** & $0.136^{* *}$ & $0.455^{* * *}$ & -0.044 & -0.136 ** & $-0.496 * * *$ & 1 & & & & & & & \\
\hline 9 & $-0.105 *$ & -0.063 & 0.02 & 0.041 & -0.04 & -0.06 & -0.002 & $0.177 * * *$ & 1 & & & & & & \\
\hline 10 & 0.045 & -0.004 & -0.021 & $-0.295^{* * *}$ & 0.026 & $0.102 *$ & $0.271^{* * *}$ & $-0.371 * * *$ & -0.05 & 1 & & & & & \\
\hline 11 & $0.164 * * *$ & 0.017 & -0.05 & $-0.261 * * *$ & -0.031 & $-0.268 * * *$ & $0.517^{* * *}$ & $-0.343 * * *$ & -0.036 & $0.161^{* * *}$ & 1 & & & & \\
\hline 12 & -0.027 & 0.028 & -0.017 & $-0.241 * * *$ & -0.024 & -0.135 ** & $0.272 * * *$ & $-0.185^{* * *}$ & 0.072 & 0.076 & $0.231^{* * *}$ & 1 & & & \\
\hline 13 & $0.109^{* *}$ & 0.032 & 0.042 & $0.111 * *$ & 0.005 & 0.0790 & $-0.178^{* * *}$ & $0.176^{* * *}$ & 0.079 & -0.078 & $-0.148^{* * * *}$ & -0.074 & 1 & & \\
\hline 14 & $-0.094 *$ & $-0.108^{*}$ & $0.178^{* * *}$ & $0.233^{* * *}$ & 0.005 & 0.0430 & $-0.132 * *$ & $0.261 * * *$ & 0.117 ** & $-0.152 * * *$ & -0.231 *** & -0.158 *** & 0.087 & 1 & \\
\hline 15 & -0.142 *** & $-0.156^{* * *}$ & 0.130 ** & $0.241^{* * *}$ & 0.100 * & -0.0580 & $-0.143^{* * * *}$ & $0.245^{* * *}$ & 0.056 & $-0.237^{* * * *}$ & -0.023 & -0.034 & 0.116 ** & $0.210^{* * *}$ & 1 \\
\hline
\end{tabular}

Note: $* * * p 0.01, * * p<0.05, * p<0.1 ; 1=$ possibility, $2=$ severity, $3=$ traditional channel, $4=$ new channel, $5=$ experience severity, $6=$ gender, $7=$ age, $8=$ education, $9=$ nationality, $10=$ occupation, $11=$ residence, $12=$ old, $13=$ child, $14=$ house, $15=$ income 
Table 4. Regression analysis results of media exposure, disaster experience and perceived prospect ranks of risk perception.

\begin{tabular}{|c|c|c|c|c|c|c|}
\hline \multirow{2}{*}{ Variables } & \multicolumn{3}{|c|}{ Possibility } & \multicolumn{3}{|c|}{ Severity } \\
\hline & Model 1 & Model 2 & Model 3 & Model 4 & Model 5 & Model 6 \\
\hline Media exposure & $\begin{array}{c}-0.402^{* * *} \\
(0.108)\end{array}$ & $\begin{array}{c}-0.401 * * * \\
(0.107)\end{array}$ & $\begin{array}{c}-0.343^{* * *} \\
(0.123)\end{array}$ & $\begin{array}{c}-0.235^{* *} \\
(0.114)\end{array}$ & $\begin{array}{c}-0.233^{* *} \\
(0.112)\end{array}$ & $\begin{array}{c}-0.242 \text { * } \\
(0.146)\end{array}$ \\
\hline Experience severity & $\begin{array}{c}0.217 * * * \\
(0.076)\end{array}$ & $\begin{array}{c}0.205^{* * *} \\
(0.075)\end{array}$ & $\begin{array}{c}0.223 * * * \\
(0.074)\end{array}$ & $\begin{array}{c}0.273^{* * *} \\
(0.098)\end{array}$ & $\begin{array}{c}0.255^{* * *} \\
(0.094)\end{array}$ & $\begin{array}{c}0.252 * * * \\
(0.096)\end{array}$ \\
\hline $\begin{array}{l}\text { Media exposure * } \\
\text { Experience severity }\end{array}$ & & -0.212 & -0.163 & & $-0.322 *$ & -0.277 \\
\hline & & $(0.147)$ & $(0.142)$ & & $(0.176)$ & $(0.182)$ \\
\hline Gender & & & $\begin{array}{l}-0.200 \\
(0.137)\end{array}$ & & & $\begin{array}{c}0.047 \\
(0.126)\end{array}$ \\
\hline Age & & & $\begin{array}{l}-0.004 \\
(0.006)\end{array}$ & & & $\begin{array}{c}-0.013 \text { ** } \\
(0.006)\end{array}$ \\
\hline Education & & & $\begin{array}{l}-0.017 \\
(0.023)\end{array}$ & & & $\begin{array}{l}-0.030 \\
(0.023)\end{array}$ \\
\hline Nationality & & & $\begin{array}{l}-0.257 \\
(0.159)\end{array}$ & & & $\begin{array}{l}-0.099 \\
(0.159)\end{array}$ \\
\hline Occupation & & & $\begin{array}{l}-0.081 \\
(0.133)\end{array}$ & & & $\begin{array}{l}-0.117 \\
(0.133)\end{array}$ \\
\hline Residence & & & $\begin{array}{c}0.008^{* *} \\
(0.004)\end{array}$ & & & $\begin{array}{c}0.002 \\
(0.004)\end{array}$ \\
\hline Ln(income) & & & $\begin{array}{c}-0.117^{*} \\
(0.069)\end{array}$ & & & $\begin{array}{l}-0.010 \\
(0.083)\end{array}$ \\
\hline Old & & & $\begin{array}{l}-0.197 \\
(0.122)\end{array}$ & & & $\begin{array}{c}0.081 \\
(0.126)\end{array}$ \\
\hline Child & & & $\begin{array}{c}0.456 * * * \\
(0.144)\end{array}$ & & & $\begin{array}{c}0.115 \\
(0.139)\end{array}$ \\
\hline House & & & $\begin{array}{c}0.011 \\
(0.132)\end{array}$ & & & $\begin{array}{l}-0.137 \\
(0.131)\end{array}$ \\
\hline Constant & $\begin{array}{c}2.645^{* * *} \\
(0.389)\end{array}$ & $\begin{array}{c}2.694^{* * *} \\
(0.392)\end{array}$ & $\begin{array}{c}4.045 * * * \\
(0.841)\end{array}$ & $\begin{array}{c}3.409 * * * \\
(0.557)\end{array}$ & $\begin{array}{c}3.483^{* * *} \\
(0.539)\end{array}$ & $\begin{array}{c}4.535^{* * *} \\
(1.044)\end{array}$ \\
\hline $\mathrm{F}$ & $10.030^{* * *}$ & $8.185^{* * *}$ & $4.338^{* * *}$ & $7.831^{* * *}$ & $5.752 * * *$ & $2.096^{* *}$ \\
\hline $\mathrm{R}^{2}$ & 0.066 & 0.071 & 0.139 & 0.050 & 0.063 & 0.092 \\
\hline Observations & 327 & 327 & 327 & 327 & 327 & 327 \\
\hline
\end{tabular}

Note: Robust standard errors in parentheses; ${ }^{* * *} p<0.01{ }^{* *} p<0.05,{ }^{*} p<0.1$.

To further explore which media exposures have a greater influence on residents' perceived prospect ranks of disaster risk perception, media exposure was further divided into traditional and new media exposure forms, based on the analysis in Table 4. An ordinary least square method econometric model was formed to further explore the regression analysis results of traditional and new media exposure, disaster experience, and perceived prospect ranks of risk perception. The settings of each model are the same as those of Models 1-6.

As shown in Tables 4 and 5, all models passed the overall significance test, indicating that at least one independent variable in the model created by the study had a significant correlation with the dependent variable. Furthermore, according to the $\mathrm{R}^{2}$ of the models, all model independent variables explained approximately $6-14 \%$ of the variation of the dependent variables.

\subsubsection{Correlations between Media Exposure and Perceived Prospect Ranks of Risk Perception}

As shown in Table 4, media exposure was negatively correlated with the perceived prospect ranks of the probability and severity of disasters. Thus, the higher the media exposure score, the lower the perceived prospect ranks of the probability and severity of disasters. More precisely, when other conditions remained unchanged, with every one-unit increase in media exposure score, there were 0.343-unit (Model 3) and 0.242-unit (Model 6) reductions in the perceived prospect ranks of the probability and severity of a disaster, respectively. 
Table 5. Regression analysis results of traditional and new media exposure, disaster experience and perceived prospect ranks of risk perception.

\begin{tabular}{|c|c|c|c|c|c|c|c|c|}
\hline \multirow{2}{*}{ Variables } & \multicolumn{4}{|c|}{ Possibility } & \multicolumn{4}{|c|}{ Severity } \\
\hline & Model 7 & Model 8 & Model 9 & Model 10 & Model 11 & $\begin{array}{l}\text { Model } \\
12\end{array}$ & $\begin{array}{c}\text { Model } \\
13\end{array}$ & $\begin{array}{c}\text { Model } \\
14\end{array}$ \\
\hline Traditional channel & $\begin{array}{l}-0.160 \\
(0.172)\end{array}$ & $\begin{array}{l}-0.156 \\
(0.170)\end{array}$ & $\begin{array}{l}-0.142 \\
(0.171)\end{array}$ & $\begin{array}{l}-0.111 \\
(0.170)\end{array}$ & $\begin{array}{c}-0.434 * * * \\
(0.164)\end{array}$ & $\begin{array}{c}-0.428^{* *} \\
(0.171)\end{array}$ & $\begin{array}{c}-0.412 * * \\
(0.164)\end{array}$ & $\begin{array}{c}-0.349^{*} \\
(0.185)\end{array}$ \\
\hline New channel & $\begin{array}{c}-0.149 * * * \\
(0.042)\end{array}$ & $\begin{array}{c}-0.149 * * * \\
(0.042)\end{array}$ & $\begin{array}{c}-0.155^{* * * *} \\
(0.042)\end{array}$ & $\begin{array}{c}-0.137^{* * *} \\
(0.048)\end{array}$ & $\begin{array}{l}-0.039 \\
(0.044)\end{array}$ & $\begin{array}{l}-0.038 \\
(0.044)\end{array}$ & $\begin{array}{l}-0.046 \\
(0.044)\end{array}$ & $\begin{array}{l}-0.049 \\
(0.055)\end{array}$ \\
\hline Experience severity & $\begin{array}{c}0.220^{* * *} \\
(0.076)\end{array}$ & $\begin{array}{c}0.222 * * * \\
(0.078)\end{array}$ & $\begin{array}{c}0.200 * * \\
(0.078)\end{array}$ & $\begin{array}{c}0.220^{* * *} \\
(0.078)\end{array}$ & $\begin{array}{c}0.265^{* * *} \\
(0.098)\end{array}$ & $\begin{array}{c}0.268^{* * *} \\
(0.099)\end{array}$ & $\begin{array}{l}0.240^{* *} \\
(0.093)\end{array}$ & $\begin{array}{c}0.238^{* *} \\
(0.096)\end{array}$ \\
\hline $\mathrm{X} 1$ & & $\begin{array}{l}-0.052 \\
(0.217)\end{array}$ & & $\begin{array}{l}-0.009 \\
(0.203)\end{array}$ & & $\begin{array}{l}-0.080 \\
(0.324)\end{array}$ & & $\begin{array}{l}-0.031 \\
(0.326)\end{array}$ \\
\hline $\mathrm{X} 2$ & & & $\begin{array}{l}-0.083 \\
(0.055)\end{array}$ & $\begin{array}{l}-0.068 \\
(0.052)\end{array}$ & & & $\begin{array}{c}-0.105^{*} \\
(0.060)\end{array}$ & $\begin{array}{l}-0.098 \\
(0.061)\end{array}$ \\
\hline Gender & & & & $\begin{array}{l}-0.189 \\
(0.138)\end{array}$ & & & & $\begin{array}{c}0.043 \\
(0.125)\end{array}$ \\
\hline Age & & & & $\begin{array}{l}-0.005 \\
(0.006)\end{array}$ & & & & $\begin{array}{c}-0.012 * \\
(0.007)\end{array}$ \\
\hline Education & & & & $\begin{array}{l}-0.016 \\
(0.023)\end{array}$ & & & & $\begin{array}{l}-0.031 \\
(0.023)\end{array}$ \\
\hline Nationality & & & & $\begin{array}{l}-0.256 \\
(0.160)\end{array}$ & & & & $\begin{array}{l}-0.100 \\
(0.159)\end{array}$ \\
\hline Occupation & & & & $\begin{array}{l}-0.090 \\
(0.136)\end{array}$ & & & & $\begin{array}{l}-0.097 \\
(0.133)\end{array}$ \\
\hline Residence & & & & $\begin{array}{c}0.008^{* *} \\
(0.004)\end{array}$ & & & & $\begin{array}{c}0.002 \\
(0.004)\end{array}$ \\
\hline Ln(income) & & & & $\begin{array}{c}-0.117^{*} \\
(0.070)\end{array}$ & & & & $\begin{array}{l}-0.009 \\
(0.084)\end{array}$ \\
\hline Old & & & & $\begin{array}{l}-0.199 \\
(0.122)\end{array}$ & & & & $\begin{array}{c}0.095 \\
(0.127)\end{array}$ \\
\hline Child & & & & $\begin{array}{c}0.454^{* * *} \\
(0.144)\end{array}$ & & & & $\begin{array}{c}0.119 \\
(0.138)\end{array}$ \\
\hline House & & & & $\begin{array}{c}0.002 \\
(0.133)\end{array}$ & & & & $\begin{array}{l}-0.130 \\
(0.133)\end{array}$ \\
\hline Constant & $\begin{array}{c}2.482^{* * *} \\
(0.468)\end{array}$ & $\begin{array}{c}2.463^{* * *} \\
(0.469)\end{array}$ & $\begin{array}{c}2.555^{* * *} \\
(0.467)\end{array}$ & $\begin{array}{c}3.949^{* * *} \\
(0.863)\end{array}$ & $\begin{array}{c}3.827^{* * *} \\
(0.584)\end{array}$ & $\begin{array}{c}3.797^{* * *} \\
(0.614)\end{array}$ & $\begin{array}{c}3.919^{* * *} \\
(0.564)\end{array}$ & $\begin{array}{c}4.774 * * * \\
(1.075)\end{array}$ \\
\hline $\mathrm{F}$ & $6.729 * * *$ & $5.033 * * *$ & $6.536^{* * *}$ & $3.831^{* * *}$ & $6.397^{* * *}$ & $4.918^{* * *}$ & $4.930^{* * *}$ & $2.224^{* * * *}$ \\
\hline R-squared & 0.067 & 0.067 & 0.074 & 0.142 & 0.059 & 0.059 & 0.070 & 0.097 \\
\hline Observations & 327 & 327 & 327 & 327 & 327 & 327 & 327 & 327 \\
\hline
\end{tabular}

Note: Robust standard errors in parentheses; ${ }^{* *} p<0.01$, ${ }^{* *} p<0.05,{ }^{*} p<0.1 ; \mathrm{X} 1$ and $\mathrm{X} 2$ refer to traditional channel $\times$ experience severity and new channel $\times$ experience severity, respectively.

Table 5 shows that, although traditional and new media exposure forms were negatively correlated with the perceived prospect ranks of the probability and severity of a disaster, traditional media exposure was only significantly negatively correlated with the perceived prospect ranks of the severity of a disaster, while new media exposure was only significantly negatively correlated with the perceived prospect ranks of the probability of a disaster. Specifically, with every one-unit increase in the traditional media exposure score, there was a 0.369 -unit reduction in the perceived prospect ranks of the severity of a disaster (Model 14). Likewise, with every one-unit increase in the new media exposure score, there was a 0.137 -unit reduction in the perceived prospect ranks of the probability of a disaster (Model 10).

\subsubsection{Correlations between Disaster Experiences and Perceived Prospect Ranks of Risk Perception}

As shown in Tables 4 and 5, experience severity was positively and significantly correlated with the perceived prospect ranks of the probability and severity of a disaster. Therefore, the higher the severity score of residents' disaster experience, the higher their perceived prospect ranks of the probability and severity of a disaster. Specifically, for every one-unit increase in the severity experience score, there were 0.223 (Model 3) and 0.252 (Model 6) unit increases in the perceived prospect ranks of the probability and severity of a disaster, respectively. 
4.3.3. Media Exposure Moderates the Relationship between Residents' Disaster Experience and Perceived Prospect Ranks of Risk Perception

As shown in Table 4 , the interaction item (media exposure $\times$ experience severity) was significantly negatively correlated with the perceived prospect ranks of severity of a disaster only at the level of 0.1 (Model 5), but was not significantly correlated with the perceived prospect ranks of the probability of a disaster. Therefore, media exposure slightly reduced the severity perception of disaster experience, and thus reduced the perceived prospect ranks of severity of a disaster. Specifically, for every 1 unit increase in the interaction item (media exposure $\times$ experience severity), there was a 0.322 unit decrease in the perceived prospect ranks of the severity of a disaster (Model 5).

As shown in Table 5, although there was a negative correlation between traditional media exposure and perceived prospect ranks of the severity of a disaster, the correlation coefficient was not significant. The interaction item (new media exposure $\times$ experience severity) was not significantly correlated with the perceived prospect ranks of the probability of a disaster but was significantly negatively correlated with the perceived prospect ranks of the severity of a disaster (Model 13). Therefore, new media exposure influenced the relationship between perceived severity of disaster experience and perceived prospect ranks of the severity of a disaster. Specifically, for every one-unit increase in the interaction item (new media exposure $\times$ experience severity), there was a 0.105 unit decrease in the perceived prospect ranks of the severity of a disaster (Model 13).

4.3.4. Correlations between Social and Economic Characteristics of Individuals and Families, and Perceived Prospect Ranks of Risk Perception

As shown in Tables 4 and 5, aspects of the resident's age, family income, and having children under 6 years old were significantly correlated with the perceived prospect ranks of the probability of a disaster. Residents who lived longer and had children under the age of six scored higher on the perceived prospect ranks of the probability of a disaster, and the higher the family's annual cash income, the lower their score for the perceived prospect ranks of the probability of a disaster. In addition, the respondent age was negatively correlated with the perceived prospect ranks of the severity of a disaster, indicating that the older the respondent age, the lower their score of the perceived severity of a disaster. Gender, occupation, ethnicity, occupants aged over 64 years old, and housing material were all not significantly correlated with the perceived prospect ranks of probability and severity of a disaster.

\section{Discussion}

Compared with the existing studies, the marginal contribution of this study is as follows: first, the empirical study analyzes the relationship between media exposure, disaster experience and perceived prospect ranks of risk perception. It is worth mentioning that when exploring the correlation between media exposure and residents' perceived prospect ranks of disaster risk perception, we further divided media exposure into new media exposure and old media exposure, and respectively explored the correlation between the two and residents' perceived prospect ranks of disaster risk perception, and obtained some interesting results. Second, the object of this study is the farmers in earthquake disaster threat areas of China. These groups are generally vulnerable due to their resource endowment. However, this group has received relatively little attention in previous studies. In general, the design of the research program, the concern of the research group and the research results can provide some references and inspirations for the formulation and behavioral decision-making of disaster prevention and mitigation policies of the residents in disaster threat areas.

Media exposure is an important factor affecting residents' perceived prospect ranks of disaster risk perception. However, inconsistent with the research results of Basolo et al. [7], Zhu and Yao [34], Fleming et al. [46] and Hong et al. [10], which found that media exposure could significantly improve residents' perceived prospect ranks of disaster risk perception, and with research hypothesis $\mathrm{H} 1$, the results from the present study showed that media exposure was significantly and negatively 
correlated with the perceived prospect ranks of the probability and severity of a disaster. This study demonstrated that both traditional and new media forms were important factors affecting residents' perceived prospect ranks of disaster risk perception. Among them, inconsistent with hypothesis H1a, the study found that the higher the frequency of traditional media used, the lower the score of the perceived prospect ranks of the severity of a disaster. Inconsistent with research hypothesis H1b, the higher the frequency of new media used, the lower the score of the perceived prospect ranks of the probability of a disaster. Possible reasons for this are as follows.

One possibility is the difference in core variables measured. As for the measurement of media exposure, some previous studies only focus on a certain category (for example, Fleming et al. [46] focuses on traditional media newspapers), and some focus on the integration of media (for example, Hong et al. [10] focuses on the media exposure of the combination of traditional media and new media). As for the measurement of perceived prospect ranks of disaster risk perception, most studies do not subdivide it as this study does, but obtain a comprehensive disaster risk perception (for example, Hong et al. [10]'s disaster risk perception is a comprehensive measure of residents' perception of the severity of various disasters). Different measurement criteria may lead to different research results.

Second, it may be related to the speed and quality of information transmitted by traditional media and new media. The study area of this study is the earthquake disaster threat area in China, and these areas are mostly relatively poor mountainous areas. Driven by economic interests, a large number of young people go out for work, leaving behind relatively old people with relatively few years of education [27,63-70]. In the face of the threat of earthquake disaster, TV is generally the most important traditional media channel for the elderly to obtain disaster information (the results of this study also found that residents get disaster information most frequently from TV). At the same time, with the development of social economy, mobile phones, especially old ones which can only make phone calls and receive information, are widely popular in rural China. Because of the convenience and low cost of receiving information by mobile phone, it often becomes an important channel for grass-roots governments to release official information about disasters and an important carrier for residents to transmit information to each other. Since rural residents generally have a low level of education and are more susceptible to the "rumor" of the epidemic, grass-roots governments generally only promptly report the occurrence of the disaster (such as the magnitude of the aftershocks) and tell residents to pay attention to the safety of life and property when disseminating disaster-related information through new media channels such as mobile phones. Therefore, the new media represented by mobile phones is more to help residents correctly understand the possibility of disaster and improve their perceived prospect ranks of the possibility of disaster. At the same time, the traditional media, represented by TV, generally reports disaster-related information confirmed and approved by the superior government (generally at the level of district, county or above). These messages typically lag behind those received via mobile phone. However, this information can better reflect the actual severity of the disaster (for example, TV news can directly tell residents the specific casualties caused by the earthquake). Therefore, the traditional media, represented by TV, mainly helps residents to correctly understand the seriousness of disasters and improve their perceived prospect ranks of severity of the disasters (For example, residents use TV to learn about casualties and damage caused by disasters).

Third, the sample size of this study is only 327 samples, relatively small, and the results of the model estimate may be discounted. This may also affect the results of this study.

Meanwhile, it is interesting to note that, as shown in Table 2, residents mainly obtain disaster information through TV and mobile phones, which is quite different from other countries. In some other countries, many studies have found that in the face of the impact of disasters, traditional media, such as television and radio, are considered to be the most frequently used channels for residents to receive information [12,71-74]. Meanwhile, the usefulness of traditional media is higher than that of new media [12], and these results are especially true for remote areas. The possible reasons for this are geographical differences and residents' usage habits. Limited by geographical location (most of the surveyed areas in this study are mountainous) and usage habits, Chinese rural residents read fewer 
newspapers and magazines and use fewer radios. The elderly mainly receive disaster information through television news. Although some elderly people do receive disaster information released by the government through mobile phones, younger people are more inclined to use mobile phones and the internet to obtain disaster information. The implication is that the government should consider television, mobile phones, and the internet to publicize or convey disaster-related information in remote hill-top settlements. Moreover, the government should also pay attention to information accuracy and quality, and reduce the spread of false information in disaster-threatened areas. Other means of information dissemination should also be considered to avoid the impact of power failure and network interruption caused by disasters.

Consistent with the research results of $\mathrm{H} 2$ and the results of the study by Botzen et al. [50] and $\mathrm{Xu}$ et al. [22], the present study found that residents' disaster experience was significantly and positively correlated with the perceived prospect ranks of probability and severity of a disaster. However, inconsistent with hypotheses $\mathrm{H} 3, \mathrm{H} 3 \mathrm{a}$ and $\mathrm{H} 3 \mathrm{~b}$, this study found that media exposure was significantly and negatively correlated with the perceived prospect ranks of the severity of a disaster, but not significantly correlated with the perceived prospect ranks of the probability of a disaster. By subdividing media exposure into traditional and new media exposure, the study found that only new media exposure was significantly negatively correlated with the perceived prospect ranks of the severity of a disaster. Therefore, the type of media platform influences the perceived prospect ranks of the severity of a disaster. The aim is to urge residents to pay attention to information about disaster severity and plan appropriate preparation strategies. Because people are worried about how an earthquake will impact their families and villages, they will pay more attention to the possibility and severity of the disaster. Some studies found the existence of a "negativity bias" phenomenon in behavioral decisions (e.g., [75-79]). In other words, faced with the threat of disaster, residents have a stronger behavioral response to negative news and are more willing to make behavioral decisions in response to negative information. Therefore, before the disaster information is uncertain, residents in earthquake-prone areas (with rich disaster experience) may tend to make a "negative" assessment of the perceived prospect ranks of severity of a disaster. At this time, the rapid transmission of disaster information by new media (mainly mobile phones) (such as clearly telling residents where and how big the earthquake disaster is) can reduce the uncertainty of information and clarify the actual situation of the disaster, thus reducing the awareness of perceived prospect ranks of the severity of a disaster. Therefore, the interaction between new media exposure and the severity of disaster experience was only negatively correlated with the perceived prospect ranks of severity of a disaster.

\section{Conclusions}

Based on the survey data of 327 households in four counties located in the worst-hit areas of the Sichuan earthquake in China, the present study analyzed the characteristics and associations of residents' media exposure, disaster experience, and perceived prospect ranks of disaster risk perception, and obtained the following conclusions.

(1) Rural households relied predominately on television broadcasts from traditional media, and on mobile phones and internet content from new media, to obtain disaster information. From the residents surveyed, $90 \%$ believed that a disaster experience was serious, $82 \%$ considered that another major earthquake would seriously affect their lives and property, while approximately $40 \%$ of the residents did not believe there would be another major earthquake in the next 10 years.

(2) Media exposure was negatively correlated with the perceived prospect ranks of the probability and severity of a disaster. The higher media exposure, the less likely that residents assign higher ranks to the probability and severity of disasters. Traditional media exposure was only significantly negatively correlated with the perceived prospect ranks of the severity of a disaster, while new media exposure was only significantly negatively correlated with the perceived prospect ranks of probability of a disaster. The experience severity was significantly positively correlated with the perceived prospect 
ranks of the probability and severity of a disaster. The higher the disaster severity experience, the more likely that residents would assign higher ranks to the probability and severity of disasters.

(3) The moderating effect between media exposure and disaster severity experience was significantly negatively correlated with the perceived prospect ranks of severity of a disaster; therefore, media exposure can slightly reduce the severity of disaster experience, and thus reduce the perceived prospect ranks of the severity of a disaster. The moderating effect between new media exposure and the disaster severity experience was significantly negatively correlated with the perceived prospect ranks of the severity of a disaster, indicating that new media exposure influences the perceived prospect ranks of the severity of a disaster.

This research has some limitations. For example, the study only focused on the association between media exposure, disaster experience, and disaster risk perception in earthquake regions. Whether similar conclusions apply to other types of disasters requires further testing. In addition, this study investigated the impact of the sources of media information and its use frequency on residents' disaster risk perception, but it did not consider the impact of the quality of media information on residents' disaster risk perception. Further research should be performed to explore these associations. Additionally, the focus group of this study is the special group of farmers in the earthquake disaster threat areas of China. Due to the differences in resource endowment and cultural background, whether the research results are applicable to the urban residents threatened by the disaster needs to be further verified.

Author Contributions: Conceptualization, D.X.; Data curation, D.X.; Funding acquisition, D.X.; Investigation, L.Z., C.Q. and Z.Y.; Methodology, L.Z., X.D., C.Q. and Z.Y.; Visualization, X.D.; Writing一original draft, D.X. and L.Z.; Writing-review \& editing, D.X. All authors have read and agree to the published version of the manuscript.

Funding: This research was funded by National Natural Science Foundation of China (No. 41801221), the Dual Support Plan of Sichuan Agricultural University (Grant No. 1921993045), the innovation training program of Sichuan Agricultural University in 2019 (No. 2019106226105) and Undergraduate research interest cultivation program in 2020 of Sichuan agricultural university (No. 2020466; No. 2020465).

Acknowledgments: We gratefully acknowledge financial support from National Natural Science Foundation of China (No. 41801221), the Dual Support Plan of Sichuan Agricultural University (Grant No. 1921993045), the innovation training program of Sichuan Agricultural University in 2019 (No. 2019106226105) and Undergraduate research interest cultivation program in 2020 of Sichuan agricultural university (No. 2020466; No. 2020465). The authors also extend great gratitude to the anonymous reviewers and editors for their helpful review and critical comments.

Conflicts of Interest: The authors declare no conflict of interest.

\section{References}

1. Davis, C.; Keilis-Borok, V.; Molchan, G.; Shebalin, P.; Lahr, P.; Plumb, C. Earthquake prediction and disaster preparedness: Interactive analysis. Nat. Hazards Rev. 2010, 11, 173-184. [CrossRef]

2. Davis, C.; Keilis-Borok, V.; Kossobokov, V.; Soloviev, A. Advance prediction of the March 11, 2011 great east Japan earthquake: A missed opportunity for disaster preparedness. J. Disaster Risk Reduct. 2012, 1, 17-32. [CrossRef]

3. Flint, C.G.; Stevenson, J. Building community disaster preparedness with volunteers: Community emergency response teams in Illinois. Nat. Hazards Rev. 2010, 11, 118-124. [CrossRef]

4. Hoffmann, R.; Muttarak, R. Learn from the past, prepare for the future: Impacts of education and experience on disaster preparedness in the Philippines and Thailand. World Dev. 2017, 96, 32-51. [CrossRef]

5. Sun, Y.Y.; Sun, J.K. Perception, preparedness, and response to tsunami risks in an aging society: Evidence from Japan. Saf. Sci. 2019, 118, 466-474. [CrossRef]

6. Godschalk, D.; Rose, A.; Mittler, E.; Porter, K.; West, C.T. Estimating the value of foresight: Aggregate analysis of natural hazard mitigation benefits and costs. J. Environ. Plan. Manag. 2009, 52, 739-756. [CrossRef]

7. Basolo, V.; Steinberg, L.J.; Burby, R.J.; Levine, J.; Cruz, A.M.; Huang, C. The effects of confidence in government and information on perceived and actual preparedness for disasters. Environ. Behav. 2008, 41, 338-364. [CrossRef] 
8. Steinberg, L.J.; Basolo, V.; Burby, R.; Levine, J.N.; Maria Cruz, A. Joint seismic and technological disasters: Possible impacts and community preparedness in an urban setting. Nat. Hazards Rev. 2004, 5, 159-169. [CrossRef]

9. Xu, D.D.; Peng, L.; Liu, S.Q.; Wang, X.X. Influences of Risk Perception and Sense of Place on Landslide Disaster Preparedness in Southwestern China. J. Disaster Risk Sci. 2018, 9, 167-180. [CrossRef]

10. Hong, Y.X.; Kim, J.S.; Xiong, L.H. Media exposure and individuals' emergency preparedness behaviors for coping with natural and human-made disasters. J Environ. Psychol. 2019, 63, 82-91. [CrossRef]

11. Lin, C.C.; Siebeneck, L.K.; Lindell, M.K.; Prater, C.S.; Wu, H.C.; Huang, S.-K. Evacuees' information sources and reentry decision making in the aftermath of Hurricane Ike. Nat. Hazards 2013, 70, 865-882. [CrossRef]

12. Steelman, T.A.; McCaffrey, S.M.; Velez, A.-L.K.; Briefel, J.A. What information do people use, trust, and find useful during a disaster? Evidence from five large wildfires. Nat. Hazards 2015, 76, 615-634. [CrossRef]

13. Ainuddin, S.; Kumar Routray, J.; Ainuddin, S. People's risk perception in earthquake prone Quetta city of Baluchistan. J. Disaster Risk Reduct. 2014, 7, 165-175. [CrossRef]

14. Henrich, L.; Mcclure, J.; Crozier, M. Effects of risk framing on earthquake risk perception: Life-time frequencies enhance recognition of the risk. J. Disaster Risk Reduct. 2015, 13, 145-150. [CrossRef]

15. Tveiten, C.K.; Albrechtsen, E.; Wærø, I.; Wahl, A.M. Building resilience into emergency management. Saf. Sci. 2012, 50, 1960-1966. [CrossRef]

16. Armas, I. Earthquake risk perception in Bucharest, Romania. Risk Anal. 2006, 26, 1223-1234. [CrossRef]

17. Bubeck, P.; Botzen, W.J.W.; Aerts, J.C.J.H. A review of risk perceptions and other factors that influence flood mitigation behavior. Risk Anal. 2012, 32, 1481-1495. [CrossRef]

18. Sun, Y.Y.; Han, Z.Q. Climate Change Risk Perception in Taiwan: Correlation with Individual and Societal Factors. Int. J. Environ. Res. Public Health 2018, 15, 91. [CrossRef]

19. Lindell, M.K. North American Cities at Risk: Household Responses to Environmental Hazards; Joffe, H., Rossetto, T., Adams, J., Eds.; Springer: New York, NY, USA, 2013; pp. 109-130.

20. Lindell, M.K.; Perry, R.W. Household adjustment to earthquake hazard: A review of research. Environ. Behav. 2000, 32, 461-501. [CrossRef]

21. Solberg, C.; Rossetto, T.; Joffe, H. The social psychology of seismic hazard adjustment: Re-evaluating the international literature. Nat. Hazards Earth Syst. Sci. 2010, 10, 1663-1677. [CrossRef]

22. Xu, D.D.; Peng, L.; Liu, S.Q.; Su, C.J.; Wang, X.X.; Chen, T.T. Influences of mass monitoring and mass prevention systems on peasant households' disaster risk perception in the landslide-threatened Three Gorges Reservoir area, China. Habitat Int. 2016, 58, 23-33. [CrossRef]

23. Peng, L.; Xu, D.D.; Wang, X.X. Vulnerability of rural household livelihood to climate variability and adaptive strategies in landslide-threatened western mountainous regions of the Three Gorges Reservoir area, China. Clim. Dev. 2019, 11, 469-484. [CrossRef]

24. Xu, D.; Yong, Z.; Deng, X.; Liu, Y.; Huang, K.; Zhou, W.; Ma, Z. Financial Preparation, Disaster Experience, and Disaster Risk Perception of Rural Households in Earthquake-Stricken Areas: Evidence From the Wenchuan and Lushan Earthquakes in China's Sichuan Province. Int. J. Environ. Res. Public Health 2019, 16, 3345. [CrossRef]

25. Peng, L.; Tan, J.; Lin, L.; Xu, D.D. Understanding sustainable disaster mitigation of stakeholder engagement: Risk perception, trust in public institutions, and disaster insurance. Sustain. Dev. 2019, 27, 885-897. [CrossRef]

26. Xu, D.D.; Peng, L.; Liu, S.Q.; Su, C.J.; Wang, X.X.; Chen, T.T. Influences of migrant work income on the poverty vulnerability disaster threatened area: A case study of the Three Gorges Reservoir area, China. J. Disaster Risk Reduct. 2017, 22, 62-70. [CrossRef]

27. Xu, D.D.; Deng, X.; Hang, K.; Liu, Y.; Yong, Z.L.; Liu, S.Q. Relationships between labor migration and cropland abandonment in rural China from the perspective of village types. Land Use Policy 2019, 88. [CrossRef]

28. CNSB (China National Statistical Bureau). China Yearbook of Household Survey in 2017; China Statistical Press: Beijing, China, 2018. (In Chinese)

29. Xu, D.D.; Liu, E.L.; Wang, X.X.; Tang, H.; Liu, S.Q. Rural households' livelihood capital, risk perception, and willingness to purchase earthquake disaster insurance: Evidence from southwestern China. Int. J. Environ. Res. Public Health 2018, 15, 1319. [CrossRef] 
30. Chatterjee, C.; Mozumder, P. Understanding household preferences for hurricane risk mitigation information: Evidence from survey responses. Risk Anal. 2014, 34, 984-996. [CrossRef]

31. Jung, J.Y.; Moro, M. Multi-level functionality of social media in the aftermath of the Great East Japan Earthquake. Disasters 2014, 38, s123-s143. [CrossRef]

32. Lee, K. The role of media exposure, social exposure and biospheric value orientation in the environmental attitude-intention-behavior model in adolescents. J. Environ. Psychol. 2011, 31, 301-308. [CrossRef]

33. Paek, H.J.; Hilyard, K.; Freimuth, V.; Barge, J.K.; Mindlin, M. Theory-based approaches to understanding public emergency preparedness: Implications for effective health and risk communication. J. Health Commun. 2010, 15, 428-444. [CrossRef] [PubMed]

34. Zhu, W.; Yao, N. Public risk perception and intention to take actions on city smog in China. Hum. Ecol. Risk Assess. 2018, 1-16. [CrossRef]

35. Brenkert-Smith, H.; Dickinson, K.L.; Champ, P.A.; Flores, N. Social amplification of wildfire risk: The role of social interactions and information sources. Risk Anal. 2012, 33, 800-817. [CrossRef] [PubMed]

36. Bunce, S.; Partridge, H.; Davis, K. Exploring information experience using social media during the 2011 Queensland Floods: A pilot study. Aust. Libr. J. 2012, 61, 34-45. [CrossRef]

37. Maidl, E.; Buchecker, M. Raising risk preparedness by flood risk communication. Nat. Hazard Earth Syst. 2015, 15, 1577-1595. [CrossRef]

38. Wood, M.M.; Mileti, D.S.; Kano, M.; Kelley, M.M.; Regan, R.; Bourque, L.B. Communicating actionable risk for terrorism and other hazards. Risk Anal. 2011, 32, 601-615. [CrossRef]

39. Hajito, K.W.; Gesesew, H.A.; Bayu, N.B.; Tsehay, Y.E. Community awareness and perception on hazards in Southwest Ethiopia: A cross-sectional study. J. Disaster Risk Reduct. 2015, 13, 350-357. [CrossRef]

40. Lindell, M.K.; Perry, R.W. The protective action decision model: Theoretical modifications and additional evidence. Risk Anal. 2011, 32, 616-632. [CrossRef]

41. Liu, T.; Jiao, H. How does information affect fire risk reduction behaviors? Mediating effects of cognitive processes and subjective knowledge. Nat. Hazards 2017, 90, 1461-1483. [CrossRef]

42. Kavota, J.K.; Kamdjoug, J.R.K.; Wamba, S.F. Social media and disaster management: Case of the north and south Kivu regions in the Democratic Republic of the Congo. Int. J. Inf. Manag. 2020, 102068. [CrossRef]

43. Ahmed, Y.A.; Ahmad, M.N.; Ahmad, N.; Zakaria, N.H. Social media for knowledge-sharing: A systematic literature review. Telemat. Inform. 2019, 37, 72-112. [CrossRef]

44. Li, L.; Zhang, Q.; Tian, J.; Wang, H. Characterizing information propagation patterns in emergencies: A case study with Yiliang Earthquake. J. Inf. Manag. 2018, 38, 34-41. [CrossRef]

45. Shklovski, I.; Burke, M.; Kiesler, S.; Kraut, R. Technology adoption and use in the aftermath of Hurricane Katrina in New Orleans. Am. Behav. Sci. 2010, 53, 1228-1246. [CrossRef]

46. Fleming, K.; Thorson, E.; Zhang, Y. Going beyond exposure to local news media: An information-processing examination of public perceptions of food safety. J. Health Commun. 2006, 11, 789-806. [CrossRef]

47. Morton, T.A.; Duck, J.M. Communication and health beliefs: Mass and interpersonal influences on perceptions of risk to self and others. Commun. Res. 2001, 28, 602-626. [CrossRef]

48. Xu, D.D.; Peng, L.; Liu, S.Q.; Su, C.J.; Wang, X.X.; Chen, T.T. Influences of sense of place on farming households' relocation willingness in areas threatened by geological disasters: Evidence from China. J. Disaster Risk Sci. 2017, 8, 16-32. [CrossRef]

49. Fischhoff, B. Risk perception and communication unplugged: Twenty years of process1. Risk Anal. 1995, 15, 137-145. [CrossRef]

50. Botzen, W.J.W.; Aerts, J.C.J.H.; van den Bergh, J.C.J.M. Willingness of homeowners to mitigate climate risk through insurance. Ecol. Econ. 2009, 68, 2265-2277. [CrossRef]

51. Siegrist, M.; Gutscher, H. Flooding risks: A comparison of lay people's perceptions and expert's assessments in Switzerland. Risk Anal. 2006, 26, 971-979. [CrossRef]

52. Kasperson, R.E.; Renn, O.; Slovic, P.; Brown, H.S.; Emel, J.; Goble, R.; Ratick, S. The social amplification of risk: A conceptual framework. Risk Anal. 1988, 8, 177-187. [CrossRef]

53. Xu, D.; Qing, C.; Deng, X.; Yong, Z.; Zhou, W.; Ma, Z. Disaster Risk Perception, Sense of Pace, Evacuation Willingness, and Relocation Willingness of Rural Households in Earthquake-Stricken Areas: Evidence from Sichuan Province, China. Int. J. Environ. Res. Public Health 2020, 17, 602. [CrossRef] [PubMed]

54. Lo, A.Y.; Cheung, L.T.O. Seismic risk perception in the aftermath of Wenchuan earthquakes in Southwestern China. Nat. Hazards 2015, 78, 1979-1996. [CrossRef] 
55. Slovic, P.; Fischhoff, B.; Lichtenstein, S. Why study risk perception? Risk Anal. 1982, 2, 83-93. [CrossRef]

56. Lennart, S. Factors in risk perception. Risk Anal. 2000, 20, 1-12. [CrossRef]

57. Slovic, P. Perception of risk. Science 1987, 236, 280-285. [CrossRef]

58. Thompson, R.R.; Garfin, D.R.; Silver, R.C. Evacuation from natural disasters: A systematic review of the literature. Risk Anal. 2016, 37, 812-839. [CrossRef]

59. Peng, L.; Lin, L.; Liu, S.Q.; Xu, D.D. Interaction between risk perception and sense of place in disaster-prone mountain areas: A case study in China's Three Gorges Reservoir area. Nat. Hazards 2017, 85, 777-792. [CrossRef]

60. Ho, M.-C.; Shaw, D.; Lin, S.; Chiu, Y.-C. How do disaster characteristics influence risk perception? Risk Anal. 2008, 28, 635-643. [CrossRef]

61. Huang, S.K.; Lindell, M.K.; Prater, C.S. Who leaves and who stays? A review and statistical meta-analysis of hurricane evacuation studies. Environ. Behav. 2016, 48, 991-1029. [CrossRef]

62. Lazo, J.K.; Bostrom, A.; Morss, R.E.; Demuth, J.L.; Lazrus, H. Factors affecting hurricane evacuation intentions. Risk Anal. 2015, 35, 1837-1857. [CrossRef]

63. Xu, D.D.; Deng, X.; Guo, S.L.; Liu, S.Q. Labor migration and cropland abandonment in rural China: Empirical results and policy implications. J. Environ. Manag. 2019, 232, 738-750. [CrossRef] [PubMed]

64. Xu, D.D.; Deng, X.; Guo, S.L.; Liu, S.Q. Sensitivity of Livelihood Strategy to Livelihood Capital: An Empirical Investigation Using Nationally Representative Survey Data from Rural China. Soc. Indic Res. 2019, 144, 113-131. [CrossRef]

65. Xu, D.D.; Guo, S.L.; Xie, F.T.; Liu, S.Q.; Cao, S. The impact of rural laborer migration and household structure on household land use arrangements in mountainous areas of Sichuan Province, China. Habitat Int. 2017, 70, 72-80. [CrossRef]

66. Huang, K.; Deng, X.; Liu, Y.; Yong, Z.; Xu, D. Does off-Farm Migration of Female Laborers Inhibit Land Transfer? Evidence from Sichuan Province, China. Land 2020, 9, 14. [CrossRef]

67. Xu, D.; Yong, Z.; Deng, X.; Zhuang, L.; Qing, C. Rural-Urban Migration and its Effect on Land Transfer in Rural China. Land 2020, 9, 81. [CrossRef]

68. Xu, D.; Ma, Z.; Deng, X.; Liu, Y.; Huang, K.; Zhou, W.; Yong, Z. Relationships between Land Management Scale and Livelihood Strategy Selection of Rural Households in China from the Perspective of Family Life Cycle. Land 2020, 9, 11. [CrossRef]

69. Deng, X.; Xu, D.; Zeng, M.; Qi, Y. Does Internet use help reduce rural cropland abandonment? Evidence from China. Land Use Policy 2019, 89, 104243. [CrossRef]

70. Deng, X.; Zeng, M.; Xu, D.; Wei, F.; Qi, Y. Household Health and Cropland Abandonment in Rural China: Theoretical Mechanism and Empirical Evidence. Int. J. Environ. Res. Public Health 2019, 16, 3588. [CrossRef]

71. Becker, S.M. Emergency communication and information issues in terrorist events involving radioactive materials. Biosecur. Bioterror. 2004, 2, 195-207. [CrossRef]

72. Burger, J.; Gochfeld, M.; Jeitner, C.; Pittfield, T.; Donio, M. Trusted information sources used during and after superstorm sandy: TV and radio were used more often than social media. J. Toxicol. Environ. Health A 2013, 76, 1138-1150. [CrossRef]

73. Rundblad, G.; Knapton, O.; Hunter, P.R. Communication, perception and behaviour during a natural disaster involving a 'Do Not Drink' and a subsequent 'Boil Water' notice: A postal questionnaire study. BMC Public Health 2010, 10, 641. [CrossRef] [PubMed]

74. Wray, R.J.; Kreuter, M.W.; Jacobsen, H.; Clements, B.; Evans, R.G. Theoretical perspectives on public communication preparedness for terrorist attacks. Fam. Community Health 2004, 27, 232-241. [CrossRef] [PubMed]

75. Fiske, S.T. Thinking is for doing: Portraits of social cognition from Daguerreotype to laserphoto. J. Pers. Soc. Psychol. 1992, 63, 877-889. [CrossRef] [PubMed]

76. Siegrist, M.; Cvetkovich, G. Better Negative than Positive? Evidence of a Bias for Negative Information about Possible Health Dangers. Risk Anal. 2001, 21, 199-206. [CrossRef] [PubMed]

77. Rozin, P.; Royzman, E.B. Negativity Bias, Negativity Dominance, and Contagion. Pers. Soc. Psychol. Rev. 2001, 5, 296-320. [CrossRef] 
78. Xu, D.; Liu, Y.; Deng, X.; Qing, C.; Zhuang, L.; Yong, Z.; Huang, K. Earthquake Disaster Risk Perception Process Model for Rural Households: A Pilot Study from Southwestern China. Int. J. Environ. Res. Public Health 2019, 16, 4512. [CrossRef]

79. Zhu, D.; Xie, X.; Gan, Y. Information source and valence: How information credibility influences earthquake risk perception. J. Environ. Psychol. 2011, 31, 129-136. [CrossRef] 